\title{
Editorial: Three Perspectives of Employment Discrimination 50 Years After the Civil Rights Act-A Promise Fulfilled?
}

\author{
Eden B. King $\cdot$ Derek R. Avery $\cdot$ Paul Sackett
}

Published online: 14 September 2013

(c) Springer Science+Business Media New York 2013

\begin{abstract}
Purpose In recognition of the 50th anniversary of the Civil Rights Act of 1964, this paper reviews contradictory perspectives of the status of employment discrimination. Design/Methodology/Approach Arguments are derived from psychology, management, law, and political science to contrast perspectives that civil rights legislation has (a) done its job, (b) gone too far, and (c) not gone far enough.

Findings We determine that disagreement is inevitable and that no unified conclusion can be drawn. Recognition of the viewpoints embedded in opposing perspectives, however, offers direction for the future of organizational science and practice.

Implications Consideration of these disparate views of civil rights legislation enables thoughtful reflection on the past, present, and future of civil rights legislation.

Originality/Value This paper offers a variety of lenses through which to consider employment discrimination in the organizational sciences and underscores the value of the papers collected in the special issue.
\end{abstract}

Keywords Discrimination - Civil rights . Employment law

\footnotetext{
E. B. King $(\bowtie)$

George Mason University, Fairfax, VA, USA

e-mail: eking6@gmu.edu

D. R. Avery

Temple University, Philadelphia, PA, USA

P. Sackett

University of Minnesota, Minneapolis, MN, USA
}

The promise of America is a simple promise: Every person shall share in the blessings of this land. And they shall share on the basis of their merits as a person. They shall not be judged by their color or by their beliefs, or by their religion, or by where they were born, or the neighborhood in which they live.Lyndon Baines Johnson.

In 1964, Title VII of the Civil Rights Act (CRA) prohibited employment discrimination on the basis of race, color, religion, sex, or national origin. Over the past 50 years, this act of legislation has had a profound impact on employees and organizations across the United States (see Aiken et al. 2013). This 50th anniversary is an opportune time to reflect on the past and future of employment discrimination; indeed, the papers collected in this special issue accomplish precisely that goal.

Our purpose in this introductory article is to frame these civil rights reflections in relation to ongoing debate. We acknowledge and discuss three perspectives of the status of civil rights legislation as indicated by case law and organizational scholarship. The first perspective reflects the notion that civil rights legislation has been effective in achieving its goals and that the status quo should be maintained. This can be contrasted with the second and third perspectives, which contend that civil rights law has gone too far and not far enough, respectively. Note that our discussion of these arguments does not reflect our endorsement of these beliefs. Rather, we have included these opposing positions to allow deeper consideration of each viewpoint. We offer some resolution to the contradictions of the three perspectives in our final conclusions.

Shortly after codifying the Civil Rights Act, President Lyndon Johnson described the motivation for its passage as described in the opening quote. 50 years later, we have the 
opportunity to consider the meaning of this legislation and its evolution. In this paper, we will consider whether the promise of judgment of the basis of merit rather than identity has been achieved.

\section{Perspective 1: Civil Rights Legislation has Done Its Job}

When addressing the issue of "has civil rights legislation been successful?", much depends on how the question is framed. At first glance, one might posit that legislation would be deemed successful if it resulted in the complete elimination of discrimination. From this point of view it is easy to document that this goal has not been met. That large numbers of discrimination complaints are filed annually with the Equal Employment Opportunity Commission (EEOC), and that the EEOC continues to negotiate large-scale settlement awards with various organizations serve as evidence that discrimination remains a significant problem.

It can be argued, however, that this is not the appropriate standard for evaluating the effectiveness of legislation. Consider other acts prohibited by legislation: one is required to stop at a red light, one is required to pay taxes, one is prohibited from breaking and entering another's home, among many others. Given, the complexities of human behavior and the multiplicities of human motives, it is no surprise that laws will be violated, sometimes based on unawareness that a law is being violated (e.g., didn't see the stop sign; didn't know that a particular expense was not deductible), and sometimes based on perceived self-interest trumping societal interest (the stop sign is for the other guy; I can beat the system by claiming false deductions; I can make money by fencing stolen goods). One might propose that while legislation cannot eliminate undesirable behavior, effective legislation (a) is recognized by those who it affects, (b) provides guidance as to how to comply, (c) serves as a deterrent to the behavior, and (d) provides appropriate compensation (e.g., a make-whole remedy) to those harmed by the behavior.

By those standards, a case can be made that the civil rights legislation in the employment arena has been effective. First, the existence of the legislation is well known by both employers covered by the law and by individuals protected by the law. Informational posters about civil rights law are posted in workplaces covered by the law. College courses in management routinely include employment discrimination among the topics covered. As one indicator of the widespread awareness of the CRA, a Gallup poll late in 1999 asked a sampling of the public to identify and evaluate the most important events of the twentieth century (Newport et al. 1999). The CRA was ranked 5th (after World War II, women gaining the right to vote in 1920, dropping the atomic bomb in 1945, and the Nazi holocaust), with only $1 \%$ of respondents reporting that they were not aware of the Civil Rights Act. This recognition of the importance of the CRA also corresponds to a substantial change in attitudes. As one example, Newport, Moore, and Saad report responses to the following question, which has been included in Gallup surveys 14 times between 1958 and 1999: “If your party nominated a generally well-qualified person for president and that person happened to be black, would you vote for that person?" Those saying "yes" increased from 37 to $93 \%$ in this interval.

Second, a complex and detailed system of case law and regulatory guidance has arisen to provide a framework for how to comply with civil rights law. As one example, consider that treatment of employment testing in the CRA itself. The law contains only one sentence addressing this directly, namely, what is known as the Tower Amendment (Section $703 \mathrm{~h}$ ), which indicates that professionally developed ability tests can be used so long as they are not "designed, intended, or used" to discriminate on the basis of race, color, religion, sex, or national origin. The three words "designed, intended, or used" is relevant to the development of the theory of adverse impact, based on the reasoning that that if only intentional discrimination was to be prohibited, Congress would not have included both "intended" and "used". This notion was established in the Supreme Court's decision in Griggs v. Duke Power Co. (1971), and fleshed out in subsequent court cases and in regulatory guidance issued by federal enforcement agencies (e.g., the Uniform Guidelines on Employee Selection Procedures 1978). While the theory of adverse impact involves evidence from a series of employment decisions, case law has established procedures for examining discrimination in individual employment decisions (e.g., the Supreme Court decision in McDonnell-Douglas vs. Green). Similarly, case law and regulatory guidance provide a framework for aiding employers in compliance on issues ranging from layoffs to sexual harassment. In short, information as to how to comply with the law is readily available to employers. While specific issues still arise that are beyond the boundaries of existing case law (for examples, see Jacobs and Murphy 2012; Arthur et al. 2013; Gutman and Dunleavy 2013), they can be expected to be addressed is subsequent court rulings, thus adding to the body of knowledge on how to comply with the CRA.

Third, a case can be made that the existence of the CRA serves as a deterrent to discrimination. There are at least two bases for deterring organizational discrimination: sanctions provided by law and concern for the firm's reputation. Penalties for violation consist of make-whole remedies (e.g., back pay) in the case of institutional discrimination (e.g., adverse impact in instances where there 
is no evidence of intent to discriminate), though punitive damages can be awarded in cases of intentional discrimination. While the risk of costly settlements has deterrent value, it is likely that concern for reputation also plays a large role. No firm wants to be in the headlines regarding allegations of discrimination, much less regarding the announcement of a multi-million dollar settlement.

One must also consider discriminatory acts by agents of the organization, e.g., supervisors and managers. It can be argued that the penalties for discrimination are not sufficient to deter individual managers and supervisors from discriminating. The law targets organizations, not individuals, and organizations are liable for the actions of agents of the organization (e.g., someone in a supervisory or management role). There is no sanction per se for individuals responsible for discriminatory acts. This serves to shift the onus of preventing individual acts of discrimination by agents of the organization to the employer, in order to prevent organizational liability for actions by its agents. Organizations enact multiples strategies including (a) centralized HR systems requiring review and approval of personnel decisions (e.g., hire, fire), (b) systems requiring managerial accountability for diversity outcomes within their unit, (c) extensive training dealing with discrimination and diversity, (d) mechanisms for employees to report and seek advice regarding discriminatory actions targeted at them or at others, (e) requiring legal approval for implementation of HR systems, and (f) involvement of HR professionals and I/O psychologists knowledgeable about discrimination and diversity issues, among others. In short, organizations deter discrimination on the part their agents via control systems, accountability mechanisms, training, and other mechanisms.

Finally, the CRA provides a remedy for those harmed by discrimination. As noted, above, compensatory and/or punitive damages can be awarded, depending on whether discrimination is intended or unintended. A clear set of procedures, with specified timelines, are in place for formal charges to be filed with federal enforcement agencies, with mechanisms also provided for the pursuit of individual lawsuits should the enforcement agencies not take up the case.

In sum, the position that the current CRA and its enforcement mechanisms is on target is not based on an argument that discrimination has been eliminated, but rather that a sturdy structure is in place, such that there is widespread awareness of the law, a well-developed structure of case law and regulatory guidance to aid employers in complying with the law, a clear basis in terms of both monetary costs and reputational effects for the law serving a deterrent function, and a clear mechanism for providing compensation to victims of discrimination. It is clear that much progress remains to be made, but the framework is there.

\section{Perspective 2: Civil Rights Legislation is Misguided and Inappropriate}

We identified several arguments underlying the perspective that civil rights legislation should be reduced or eliminated. These include beliefs that the CRA (a) is fundamentally unconstitutional, (b) requires the enactment of prejudice against dominant group members, (c) is no longer needed, and (d) should favor validity above diversity. Each of these arguments is detailed below.

\section{The CRA is Unconstitutional}

The first, most extreme, and least common argument is that the application of the Civil Rights Act to private business is unconstitutional. This view was exemplified when tea party conservative (and current U.S. Senator) Ron Paul voted against a bill marking the 40th anniversary of the CRA in 2004. He argued that the act, $\cdots$ gave the federal government unprecedented power over the hiring, employee relations, and customer service practices of every business in the country. The result was a massive violation of the rights of private property and contract. Paul further explained his opposition to recognition of the CRA by stating, The federal government has no legitimate authority to infringe on the rights of private property owners to use their property as they please and to form (or not form) contracts with terms mutually agreeable to all parties. The rights of all private property owners, even those whose actions decent people find abhorrent, must be respected if we are to maintain a free society.

The issue of constitutionality of the CRA was addressed in the case Heart of Atlanta Motel v. United States, 379 U.S. 241 (1964). In this case, the Supreme Court ruled that the Interstate Commerce Clause permits Congress to enact legislation that relates to the regulation of economic exchanges across state lines. This decision upheld the CRA but is not without critics; some argue that reliance on the commerce clause to justify such acts (including the hotly contested Patient Protection and Affordable Care Act) reflects overreaching by the federal government.

\section{Civil Rights Law is Racist/Sexist}

A second and more commonly shared view supporting the perspective that civil rights laws have gone too far is the notion that enacting these laws require (or have the consequence of) racism or sexism. This idea is based on the rationale that identity-conscious policies and practices inherently involve or will result in discrimination toward dominant group members. Apfelbaum and colleagues (Apfelbaum et al. 2012) recently summarized this argument as it pertains to race by stating: "If racial minority 
status confers an advantage in hiring, in school admissions, in the drawing of voting districts, and in the selection of government subcontractors-the argument goes-then Whites' right for equal protection may be violated" (Apfelbaum et al. 2012; p. 207). The Supreme Court case of Ricci v. DeStefano (2009) directly related to such "reverse discrimination" when a city threw out the results of a promotion test that resulted in favoring White and Hispanic firefighters over African-American firefighters. Majority group members do seem to fear this potential violation of rights more broadly; results from a survey study show that White-Americans reported that prejudice toward Blacks has decreased over the past 50 years while prejudice toward Whites has increased (Norton and Sommers 2011). This is reflected in the current special issue: the tension between affirmative action policies and non-discrimination laws is described in Thompson and Morris (2013) and reflected by evidence that favoritism toward protected classes is a predictor of employment litigation (Williams et al. 2013).

Proponents of this view often offer identity-blind practices as an alternative to identity-conscious policies. Chief Justice of the Supreme Court John Roberts articulated this perspective when stating that, "The way to stop discrimination on the basis of race is to stop discriminating on the basis of race" (Parents Involved in Cmty. Sch. v. Seattle Sch. Dist. No. 1, 551 U.S. 701 2007). An identity-neutral or identity-blind position suggests that social identity does not and should not matter in employment decisions. This kind of procedure is illustrated by the University of Texas's policy of automatically admitting all high school seniors who are in the top $10 \%$ of their graduating class. In a case currently before the Supreme Court (Fisher v. University of Texas, 2012), a White-female applicant who was denied admission to the University of Texas is arguing that the $10 \%$ rule ensures fairness and a "critical mass," and thus is already sufficient for ensuring equal opportunity to the point that additional efforts are unnecessary. From this lens, additional efforts beyond the $10 \%$ rule to also consider racial minority status in admissions decisions-which could potentially favor affluent racial minority applicants_-are considered unfair, illegal, and racist.

\section{Civil Rights Law is no Longer Needed}

When ruling that identity group could only be used in reference to "holistic review" procedures (Grutter v. Bollinger 2003), Justice O'Connor's opinion specified that, "We expect that 25 years from now, the use of racial preferences will no longer be necessary to further the interest approved today." During oral arguments for the Fisher case this year, Justice Breyer noted that the court's reconsideration of the issue less than a decade later suggests that this timeline may be speeding up; "I know that time flies, but I think only nine of those years have passed."

The election of the nation's first African-American President was lauded as emblematic of a post-racial America in which voters (and presumably employers) exemplify transracial universalism [New York Times (September 2011)]. Following the logic of a post-marginalized identity society, civil rights laws are viewed as simply no longer necessary. In line with this, it appears that some Americans are pushing for the elimination of affirmative action policies. Voting records show that five of the six states (including California and Florida) that have voted on identity-conscious affirmative action policies supporting minorities have banned them.

\section{Validity Outweighs Diversity}

A final argument that is often considered by organizational psychologists involves a "diversity-validity dilemma" (Kravitz 2008; Ployhart and Holtz 2008; Pyburn et al. 2008), wherein the strongest predictors of performance are also those that create adverse impact. In their review of 16 evidence-based strategies, Ployhart and Holtz (2008) concluded that the only approach that was effective in reducing adverse impact while maintaining validity is assessing the full range of KSAOs relevant to the job. Notably, whether an organization decides to use a more or less valid selection tool is not a legal issue (see Pyburn et al. 2008), whereas a decision to use a tool with more or less impact is very much a legal concern. The diversity-validity dilemma, then, may be resolved by an organization choosing to tradeoff validity for reduced adverse impact. As Pyburn and colleagues argue, "Doing so violates no laws, but it fails to capitalize on over 80 years of research that has shown valid selection procedures can enhance job performance and utility" (p. 150). An alternative approach that would justify changes to existing employment discrimination case law would be to favor validity over diversity, arguably fulfilling organizational objectives of maximizing individual performance and organizational effectiveness.

Any one of these arguments might be sufficient to justify the perspective that civil rights legislation has gone too far. Together, they offer fuel for individuals, organizations, and opposition groups. This view, however, can be contrasted with arguments suggesting that existing legislation has not gone far enough.

\section{Perspective 3: Civil Rights Legislation has not Gone far Enough}

Though one could construct a lengthy list of reasons for arguing that the CRA of 1964 didn't go far enough, there 
are four that are probably superordinate to the other possibilities. First, as a number of recent studies clearly show, individuals continue to experience workplace discrimination on the basis of their identity group membership along a protected dimension. In short, the CRA may have outlawed it, but failed to eradicate it. Second, some of this discrimination remains traditionally overt, but a good deal of it has taken on subtler forms, such as incivility, seemingly innocuous microaggressions, harassment, or even bullying. Third, there is mounting evidence indicating that categories not protected by the CRA are being used against prospective and incumbent employees in organizational decisions. Fourth, though the CRA pushed school desegregation, it did not address funding disparities. Collectively, these four issues suggest some of the CRA's promise to eliminate the consideration of irrelevant identity information remains unfulfilled.

\section{Discrimination is Still Prevalent on Protected Categories}

Considering the first reason (i.e., there is still discrimination on the basis of protected group membership), we begin with the data. In 2005 alone, there were over 94,000 claims filed with the EEOC pertaining to violations of Title VII of the CRA and monetary settlements for this type of violation totaled \$101.3 million dollars (Goldman et al. 2006). By 2011, the number of charges had risen to an all-time high of nearly $100,000(99,947)$ and the sum of relief payments more than quadrupled to $\$ 455.6$ million (EEOC 2012). Moreover, this discrimination has not been limited to a particular type (e.g., race or sex), as recent evidence shows that each of the protected categories stipulated by the CRA continue to be problematic. For instance, a, nationally representative survey (Avery et al. 2008) indicated that more than $4 \%$ of employees believe they have been discriminated against on the basis of sex within the past year alone and more than $3 \%$ feel that their race or ethnicity was held against them during that same period. Regarding religion, King and Ahmad (2010) recently reported that Muslim job applicants, a particularly controversial religious group in the U.S. since September 11, 2001, received more negative reactions than those who were not visibly Muslim (see Ghumman et al. 2013 for a more comprehensive discussion of the literature on religious discrimination). A recent investigation by Harrison and Thomas (2009) showed colorism to be alive and well in that skin color influenced the level of bias exhibited against Black applicants to the disadvantage of those with darker skin. Finally, an entire special issue (Dietz 2010) recently documented immigrant mistreatment, illustrating that national origin discrimination remains present.
Discrimination has Evolved

Although discrimination has remained prevalent long after the passage of the CRA, the nature of this mistreatment has evolved considerably. Rather than the overt denials of opportunity on the basis of one's identity group membership typical in the past, much of the recent evidence depicts more subtle, covert types of discrimination such as bullying (Fox and Stallworth 2005), incivility (Cortina 2008), microaggressions (Sue 2008), or harassment (Schneider et al. 2000). In fact, one study found that "most experiences of ethnic harassment in the workplace during the previous 24 months included verbal ethnic harassment (i.e., ethnic slurs, derogatory ethnic comments, or ethnic jokes)" (Schneider et al. 2000, p. 3). Roughly two-thirds of participants in a more recent study (Low et al. 2007) indicated that they had been ethnically harassed verbally within the last two years. Perhaps even more telling is that a similar proportion of respondents in that study indicated that they had seen a coworker harassed based on their ethnicity suggesting that this covert form of activity does not appear to be taboo. Though this type of mistreatment is more difficult to prove in court and, arguably, harder for an employer to control, it is important to recognize that it too has a considerable negative impact on the well being of those who are unfortunate enough to experience or even witness it (e.g., Deitch et al. 2003; Low et al. 2007; Wang et al. 2011).

\section{Noteworthy Omissions}

The CRA represented a first step toward outlawing the use of many irrelevant identity markers in employment decisions. There were, however, some notable omissions. For instance, it did not provide protections against age or disability discrimination, which both remained legal until the passage of subsequent federal legislation prohibiting their usage as criteria in employment decisions. Though the age and disability oversights have since been corrected, one particularly salient identity marker has yet to be classified as a protected category-sexual orientation. As Martinez et al. (2013) discuss in great detail, this is omission is troubling for a few reasons. First, like the categories protected by federal law, an individual's sexual orientation is irrelevant to their job performance capability. Second, due to deeply ingrained prejudices against those who aren't strictly heterosexual, those in the lesbian, gay, bisexual, and transgendered community continue to be common targets for discriminatory treatment (King and Cortina 2010; Martinez et al. 2013). Not only is this an issue of social injustice, but it also creates a significant opportunity cost for organizations by introducing inefficiency in their 
personnel management (i.e., missing out on better qualified candidates due to bias).

\section{Inequitable School Funding}

Though the settlement of the historic Brown v. Topeka Board of Education case outlawed the prevailing "separate but equal" premise 10 years prior to the passage of the CRA, legislators used the CRA to institute provisions (e.g., forced busing) to aid the desegregation of public schools (Title IV). These provisions may have been well intentioned, but it appears that they missed the mark in identifying one of the key factors in reducing the disparity among public schools in the US-inequitable funding. The CRA did nothing to change the fact that public school funding is almost entirely contingent upon the size of the local tax base in which the school is located. Consequently, more affluent areas have better resourced schools and less affluent areas have poorer schools. In response to forced busing initiatives, many White Americans (particularly those with means) took the opportunity to leave urban centers with large minority populations in favor of the surrounding suburbs or relocate their children to private schools (Fairlie and Resch 2002). The residential mobility component of this reaction, also known as "White flight", reduced the tax bases of the urban schools while infusing those in the suburbs with new revenue. By failing to address this inequity, the CRA essentially allowed the continuation of separate but unequal, albeit in a new form.

Collectively, this suggests that the CRA didn't go far enough in four key ways. First, though it provided protection against discrimination on the bases of sex, race, national origin, color, and religion, it is questionable as to whether this legislation had sufficient teeth. Given that these forms of mistreatment remain commonplace nearly 50 years after the passage of the CRA (as the literature suggests), it seems that stronger legislation or more severe penalties are warranted. Second, while the act explicitly outlawed many of the prevailing forms of that era, it did not (and likely could not) anticipate the evolution of discrimination to today's more subtle actions and inactions. Consequently, some of these phenomena (e.g., microaggressions, incivility, or "glass cliff" appointments) are not necessarily illegal according to the CRA. For instance, an organization could legally discriminate against a high potential female employee by promoting her to position, where the odds of failure are disproportionately high, in effect, stacking the deck against her (Ryan and Haslam 2007). Third, it is clear that no legislation is perfect, which is why many are revisited, amended, or even removed altogether. The CRA is no exception. While laws have been enacted to redress discrimination on the basis of age and disability (physical and mental), federal protection for sexual orientation has not been forthcoming. Moreover, fewer than half of the United States of America (21 in total) have outlawed sexual orientation discrimination at the state level. Finally, by not correcting a fundamental flaw in our educational funding system, the CRA allowed for massive disparities in public school funding to continue. In at least these four key ways, the CRA didn't go far enough.

\section{Conclusions}

We began this paper with the objective of answering the question: has the promise of the CRA been fulfilled? We have provided arguments and evidence in support of three contradictory answers that represent a wide range of perspectives. It is clear from this review that a lot has happened in the past 50 years, but the ultimate resolution of these changes is much less clear. Each of the three perspectives described here has some validity-no unified conclusion exists. Instead, attempts to consider the problem of discrimination in the next 50 years must acknowledge these opposing viewpoints. The papers included in this special issue provide both context and direction guiding the future of scholarship and practice devoted to employment discrimination.

Understanding of context might begin with a look backward toward the forces that engendered and supported the CRA. In their historical review, Aiken et al. (2013) describe the CRA as the beginning of a fundamental shift in addressing racism and sexism in employment. In addition, contextual information also can be obtained through analysis of judicial decisions that reflect contemporary views of civil rights law. For example, Williams et al. (2013) identify the selection tools and processes that are litigation risks, labeling several selection system "mistakes." As another example, Thompson and Morris (2013) studied legal responses to Affirmative Action plans. The results of an analysis of 80 cases suggest that presenting evidence of statistical disparities-particularly when adjudicated by Democratic judges-can engender decisions favoring remedial need. In addition, temporary plans without reserved positions are favored. Moreover, Deitch and Hegewisch (2013) considered what happens to organizations that are subject to litigation. Their comprehensive examination of 502 consent decrees yielded substantial variability in this potential mechanism for change. Indeed, nearly $50 \%$ of consent degrees involved no meaningful substantive organizational changes. These papers help characterize the current context of employment discrimination.

The papers collected here also provide direction for understanding the future of employment discrimination. For example, Ghumman and colleagues (Ghumman et al. 2013) and Martinez and colleagues (Martinez et al. 2013) 
point to groups that are targeted by discrimination, but about which research and case law is insufficient. The former paper reviews research on religious discrimination and concludes that the increasing religious diversity of American workers, increasing expression of religious beliefs, and unique attributes of religious identities, taken with ambiguity in legal standards, compels focused attention. The latter paper draws attention to the lack of protection for sexual orientation minorities and points to organizational leaders as levers for potential change.

Guidance for the future is also available in papers that describe emergent questions about employment discrimination law. For example, Jacobs et al. (2012) use a Monte Carlo simulation to highlight the problematic nature of a growing emphasis on statistical significance testing in determining adverse impact with large sample sizes. Arthur et al. (2013) caution against making predictions about reducing adverse impact, instead suggesting that we should simply promise to offer valid and defendable assessment tools. Gutman and Dunleavy (2013) provide an overview of four central controversies involving adverse impact theory, reverse discrimination, harassment, and retaliation that have emerged in the continuing process of CRA refinement. These are areas wherein careful scrutiny continues to be needed.

The current paper highlights a lack of consensus in contemporary perspectives of the CRA and its evolution, but the responsibility for employment equality is a shared one. We hope the current discussion, and the unique papers collected in this timely special issue, shape progress over the next 50 years.

Acknowledgments Special thanks to the outstanding Guest Editorial Board for this Special Feature of the Journal of Business and Psychology: Jill Bradley-Geist, Art Brief, Joerg Dietz, Eric Dunleavy, Harold Goldstein, Irwin Goldstein, Art Gutman, Paul Hanges, Mikki Hebl, Morela Hernandez, Rick Jacobs, Jerry Kehoe, David Kravitz, Lisa Leslie, Juan Madera, Patrick McKay, Kevin Murphy, Jim Outtz, Ann Marie Ryan, Sheldon Zedeck.

\section{References}

Aiken, J., Salmon, D., \& Hanges, P. J. (2013). The origins and legacy of the Civil Rights Act of 1964. Journal of Business and Psychology, 28(4), 383-399.

Apfelbaum, E. P., Norton, M. I., \& Sommers, S. R. (2012). Racial color blindness: Emergence, practice, and implications. Current Directions in Psychological Science, 21(3), 205-209.

Arthur, W., Doverspike, D., Barret, G. V., \& Miguel, R. (2013). Chasing the Title VII holy grail: The pitfalls of guaranteeing adverse impact elimination. Journal of Business and Psychology, 28(4), 473-485.

Avery, D. R., McKay, P. F., \& Wilson, D. C. (2008). What are the odds? How demographic similarity affects the prevalence of perceived employment discrimination. Journal of Applied Psychology, 93, 235-249.
Cortina, L. M. (2008). Unseen injustice: Incivility as modern day discrimination in organizations. Academy of Management Review, 33, 55-75.

Deitch, E. A., Barsky, A., Butz, R. M., Chan, S., Brief, A. P., \& Bradley, J. C. (2003). Subtle yet significant: The existence and impact of everyday racial discrimination in the workplace. Human Relations, 56, 1299-1324.

Deitch, C., \& Hegewisch, A. (2013). Title VII sex and race discrimination litigation settlements as opportunities for organizational change. Journal of Business and Psychology, 28(4), $425-438$.

Dietz, J. (2010). Introduction to the special issue on employment discrimination against immigrants. Journal of Managerial Psychology, 25, 104-112.

EEOC (2012, January 25). Private sector bias charges hit all-time high. Retrieved January 7, 2013 from http://www.eeoc.gov/eeoc/ newsroom/release/1-24-12a.cfm.

Fairlie, R., \& Resch, A. (2002). Is there "white flight" into private schools? Evidence from the National Longitudinal Survey. Review of Economics and Statistics, 84, 21-33.

Fisher v. Univ. of Tex. at Austin, 645 F. Supp. 2d 587, 593 (2009), aff'd, 631 F.3d 213 (2011), cert. granted, 123 S. Ct. 1536 (2012).

Fox, S., \& Stallworth, L. E. (2005). Racial/ethnic bullying: Exploring links between bullying and racism in the U. S. workplace. Journal of Vocational Behavior, 66, 438-456.

Ghumman, S., Ryan, A. M., Barclay, L., \& Markel, K. (2013). Religious discrimination in the workplace: A review and examination of future trends. Journal of Business and Psychology, 28(4), 439-454.

Goldman, B. M., Gutek, B. A., Stein, J. H., \& Lewis, K. (2006). Employment discrimination in organizations: Antecedents and consequences. Journal of Management, 32, 786-830.

Gratz v. Bollinger. (2003) 539 U.S. 244.

Griggs v. Duke Power Co. (1971) 401 U.S. 424.

Grutter v. Bollinger. (2003) 539 U.S. 306.

Gutman, A., \& Dunleavy, E. (2013). Contemporary Title VII enforcement: The song remains the same? Journal of Business and Psychology, 28(4), 487-503.

Harrison, M. S., \& Thomas, K. M. (2009). The hidden prejudice in selection: A research investigation on skin color bias. Journal of Applied Social Psychology, 39, 134-168.

Heart of Atlanta Motel v. United States, 379 U.S. 241 (1964).

Jacobs, R., Murphy, K., \& Silva, J. (2012). Unintended consequences of EEO enforcement policies: Being big is worse than being bad. Journal of Business and Psychology, 28(4), 467-471.

King, E. B., \& Ahmad, A. S. (2010). An experimental field study of interpersonal discrimination toward Muslim job applicants. Personnel Psychology, 63, 881-906.

King, E. B., \& Cortina, J. M. (2010). The social and economic imperative of lesbian, gay, bisexual, and transgendered supportive organizational policies. Industrial \& Organizational Psychology, 3, 69-78.

Kravitz, D. A. (2008). The diversity-validity dilemma: Beyond selection- the role of Affirmative Action. Personnel Psychology, 61(1), 173-193.

Low, K. S. D., Radhakrishnan, P., Schneider, K. T., \& Rounds, J. (2007). The experiences of bystanders of workplace ethnic harassment. Journal of Applied Social Psychology, 37, 2261-2297.

Martinez, L. R., Ruggs, E. N., Sabat, I. E., Hebl, M. R., \& Binggeli, S. (2013). The role of organizational leaders in sexual orientation equality at organizational and federal levels. Journal of Business and Psychology, 28(4), 455-466.

New York Times (September 2011). Under Obama, is America Post Racial? Retrieved online on December 27, 2012 from: http:// www.nytimes.com/roomfordebate/2011/09/21/under-obama-isamerica-post-racial. 
Newport, F., Moore, D. W., \& Saad, L. (1999). The most important events of the century from the view point of the people. Gallup News Service, Dec. 6, 1999. Downloaded from http://www. gallup.com/poll/3427/most-important-events-century-fromviewpoint-people.aspx, January 11, 2013.

Norton, M. I., \& Sommers, S. R. (2011). Whites see racism as a zerosum game that they are now losing. Perspectives on Psychological Science, 6(3), 215-218.

Parents Involved in Cmty. Sch. v. Seattle Sch. Dist. No. 1, 551 U.S. 701 (2007).

Ployhart, R. E., \& Holtz, B. C. (2008). The diversity-validity dilemma: Strategies for reducing racioethnic and sex subgroup differences and adverse impact in selection. Personnel Psychology, 61(1), 153-172.

Pyburn, K. M, Jr, Ployhart, R. E., \& Kravitz, D. A. (2008). The diversity-validity dilemma: Overview and legal context. Personnel Psychology, 61(1), 143-151.

Ricci v. DeStefano, (2009) 129 S. CT. 2658, 2671, 174 L. Ed. 2d 490.

Ryan, M., \& Haslam, S. (2007). The glass cliff: Exploring the dynamics surrounding women's appointment to precarious leadership positions. Academy of Management Review, 32, 549-572.

Schneider, K. T., Hitlan, R. T., \& Radhakrishnan, P. (2000). An examination of the nature and correlates of ethnic harassment experiences in multiple contexts. Journal of Applied Psychology, $85,3-12$.

Sue, D. W. (2008). Racial microaggressions and worldviews. American Psychologist, 64, 220-221.

Thompson, J., \& Morris, S. B. (2013). What factors influence judges' rulings about the legality of affirmative action plans? Journal of Business and Psychology, 28(4), 411-424.

Uniform Guidelines on Employee Selection Procedures, (1978) 29 C.F.R. 1607.

Wang, J., Leu, J., \& Shoda, Y. (2011). When the seemingly innocuous "stings": Racial microaggressions and their emotional consequences. Personality and Social Psychology Bulletin, 37, $1666-1678$.

Williams, K., Schaffer, M. M., \& Ellis, L. E. (2013). Legal risk in selection: An analysis of processes and tools. Journal of Business and Psychology, 28(4), 401-410. 